\title{
Estimating Relative Technical Efficiency in Barani Agriculture: Some Further Results
}

\author{
HIMAYATULLAH
}

\section{INTRODUCTION}

The concept of technical efficiency of farms has sufficiently been detailed in the literature on agricultural economic development since Farrell (1957) and has now widely been studied by, among others, Bardhan (1973); Kalirajan and Flinn (1983); Fare, Grosskopf and Lovell (1985); Battese, Coelli and Colbi (1989); Kalirajan (1990); Battese and Coelli (1992); Himayatullah, et al. (1994); and Bashir and Himayatullah (1994).

The interest in relative economic efficiency emerged from the observation that labour intensity and yield are inversely related to farm size. Economists interpreted this result as an indication that either small and large farms faced different configurations of input and output prices, or small and large farms differed with respect to economic efficiency. Economic efficiency of a group of farms can be conceptualised as comprising two main components; technical efficiency and allocative efficiency. A group of farms may be considered technically more efficient than another group of farms if it can produce a given output with less of some or all inputs, and a group of farms may be considered allocatively more efficient than another group of farms if it is more successful in equating marginal revenue product with the marginal cost of inputs. More simply, technical efficiency involves the farm's ability to obtain the maximum possible output from a given set of resources, and allocative efficiency concerns its ability to maximise profits by equating the marginal revenue product with the marginal cost of inputs. Specifically, a group of farms that uses the best combination of inputs achieves the maximum possible output and is superior to another group of farms which does not do the same, given a similar bundle of inputs.

Himayatullah is Junior Research Specialist/Lecturer at the Institute of Development Studies (IDS), NWFP Agricultural University, Peshawar.

Author's Note: I am greatly indebted to the discussant and reviewers of this paper for their expert views and comments. 
The main objective of this paper is to estimate the behaviour of wheat producers in terms of their relative technical efficiency. Keeping in view this objective, the paper tests the hypotheses that (i) small, medium, and large farmers are equally technically efficient, and that (ii) owner cultivators, owner-cum-tenants, and tenants are equally technically efficient. The paper uses a methodology which relates technical efficiency to farm size and the tenurial status of farmers. The methodology concerns an econometric model which estimates relative technical efficiency across various groups of farms on the basis of size and tenure. The model has implications for policy purposes because it indicates whether the existing ownership and tenurial structure is detrimental to technical efficiency.

\section{METHODOLOGY}

\subsection{The Study Area}

The district of Lakki Marwat constituted the area of this study. The reasons why this district was selected for the present study are as follow. This is one of the most neglected and least developed areas of the North West Frontier Province (NWFP). Empirical research studies are lacking in this area. Most of the research studies have been concentrated in the irrigated and more developed areas of the North West Frontier Province (NWFP), with few exceptions in the southern parts other than Lakki Marwat. The study area, therefore, was selected for research purposes as it is non-irrigated and rainfed.

\subsection{Sampling and Data Collection}

The required data for the analysis of relative technical efficiency were obtained through a sample survey conducted during May, 1994 wheat harvest season. In all, 170 farmers were randomly selected from 10 purposively chosen ${ }^{1}$ villages from the study area. Before selecting sample farmers, a list of farmers was prepared in each village and stratified into (i) small, medium, and large farmers; and (ii) owner cultivators, owner-cum-tenants, and tenants, respectively. Then from each stratum, farmers were randomly selected in proportion to their population in the sample area. The distribution of the sample respondents by farm size is given in Table 1 . The sample included 60 small, 70 medium, and 40 large farmers.

The distribution of sample farmers by tenure is shown in Table 2, which shows that sample farmers included 65 owner operators, 70 owner-cum-tenants and 35 tenants. sample.

${ }^{1}$ The purposive selection of villages was made to assure maximum representativeness of the 
Table 1

Distribution of Sample Farmers by Farm Size

\begin{tabular}{lcccc}
\hline & \multicolumn{4}{c}{ Farm Size Categories (Acres) } \\
\cline { 2 - 5 } Village & $\begin{array}{c}\text { Small } \\
\text { (upto 12) }\end{array}$ & $\begin{array}{c}\text { Medium } \\
(12-25)\end{array}$ & $\begin{array}{c}\text { Large } \\
\text { (above 25) }\end{array}$ & All \\
\hline Pahar Khel & 6 & 7 & 4 & 17 \\
Shahbaz Khel & 7 & 7 & 3 & 17 \\
Jhang Khel & 8 & 5 & 2 & 15 \\
Begu Khel & 5 & 3 & 5 & 13 \\
Aba Khel & 6 & 8 & 4 & 18 \\
Pahar Khel Thal & 6 & 6 & 4 & 16 \\
Tabbi Murad & 6 & 9 & 4 & 19 \\
Landiwa & 5 & 10 & 5 & 20 \\
Wanda Mash & 6 & 6 & 4 & 16 \\
Shamoni Khattak & 5 & 6 & 5 & 19 \\
Total & 60 & 9 & 40 & 170 \\
\hline
\end{tabular}

Source: Relative Technical Efficiency Survey, 1994.

Table 2

Distribution of Sample Farmers by Tenurial Categories

\begin{tabular}{lcccc}
\hline & \multicolumn{3}{c}{ Tenurial Categories } \\
\cline { 2 - 5 } Village & Owners & $\begin{array}{c}\text { Owner-cum- } \\
\text { Tenant }\end{array}$ & Tenants & All \\
\hline Pahar Khel & 8 & 7 & 2 & 17 \\
Shahbaz Khel & 6 & 7 & 4 & 17 \\
Jhang Khel & 3 & 5 & 7 & 15 \\
Begu Khel & 7 & 3 & 3 & 13 \\
Aba Khel & 6 & 8 & 4 & 18 \\
Pahar Khel Thal & 8 & 6 & 2 & 16 \\
Tabbi Murad & 6 & 9 & 4 & 19 \\
Landiwa & 8 & 10 & 2 & 20 \\
Wanda Mash & 7 & 6 & 3 & 16 \\
Shamoni Khattak & 6 & 9 & 4 & 19 \\
Total & 65 & 70 & 35 & 170 \\
\hline
\end{tabular}

Source: Relative Technical Efficiency Survey, 1994.

\subsection{Organisation of the Survey}

Drawing of sample farmers was followed by actual collection of the required data. The responses of the sample farmers were recorded in a pre-tested 
questionnaire. The questionnaire was pretested ${ }^{2}$ by trial interviews in the survey area. The actual field data collection started in the first week of May, 1994 and continued till the end of the first week of June, 1994. The collected data were analysed with the help of a computer using an econometric model, which is discussed below.

\subsection{The Model}

In the methodology adopted here, a direct estimate was made of the production function by using various functional forms, e.g., linear, semi-logarithmic and double-logarithmic, ${ }^{3}$ for each of the six groups of farms (i.e., small, medium, large, owner-operated, owner-cum-tenanted and tenanted), and then these functions were compared. ${ }^{4}$ Tests were conducted first to determine factor-neutral and factorbiased differences in technology for each set of farms. The basic estimating equations, following Barnum and Squire (1978), may be written as:

$$
\begin{aligned}
& Y_{j}=\alpha_{0}+\beta_{0} D_{1 j}+\beta_{0} D_{2 j}+\sum_{i=1}^{3} \alpha_{i} X_{i j}+\sum_{i=1}^{3} \beta_{i} D_{1 j} X_{i j}+ \\
& \sum_{i=1}^{3} \beta_{i} D_{2 j} X_{i j}+\gamma D_{3 j}+\psi D_{4 j}+u_{j} \quad \ldots \quad \ldots \quad \ldots \\
& Y_{j}=\alpha_{0}+\beta_{0} D_{1 j}+\beta_{0} D_{2 j}+\sum_{i=1}^{3} \alpha_{i} \ln X_{i j}+\sum_{i=1}^{3} \beta_{i} D_{1 j} \ln X_{i j}+ \\
& \sum_{i=1}^{3} \beta_{i} D_{2 j} \ln X_{i j}+\gamma D_{3 j}+\psi D_{4 j}+u_{j} \quad \ldots \quad \ldots \quad \ldots \\
& \ln Y_{j}=\alpha_{0}+\beta_{0} D_{1 j}+\beta_{0} D_{2 j}+\sum_{i=1}^{3} \alpha_{i} X_{i j}+\sum_{i=1}^{3} \beta_{i} D_{1 j} X_{i j}+ \\
& \sum_{i=1}^{3} \beta_{i} D_{2 j} X_{i j}+\gamma D_{3 j}+\psi D_{4 j}+u_{j} \quad \ldots \quad \ldots \quad \ldots
\end{aligned}
$$

${ }^{2}$ The questionnaires were pre-tested by contacting 10 percent (17 farmers) of the total sample farmers in the study area.

${ }^{3}$ Since it is difficult to determine a priori which of the functional forms is the most appropriate to any particular data set, the linear, semi-logarithmic, and double-logarithmic forms were used. Both linear and double-logarithmic functional forms have their own merits and demerits which are very wellexplained in literature [Humphrey and Oxley (1976)].

${ }^{4}$ This methodology has been criticised by Nowsherwani (1966) and others on the grounds that the production function estimate is subject to the simultaneous-equation bias. This criticism, however, has successfully been answered by, among others, Zellner, Kmenta and Dreze (1966), who demonstrate that given the lag between input decisions and output which occurs in agriculture, the OLS method will give unbiased estimates of the production function. 


$$
\begin{aligned}
& Y_{j}=e^{\left(\alpha_{0}+\beta_{0} D_{1 j}+\beta_{0} D_{2 j}\right)} \prod_{i=1}^{3} X_{i j}^{\alpha_{i}} \prod_{i=1}^{3} X_{i j}^{\beta_{i} D_{1 j}}
\end{aligned}
$$

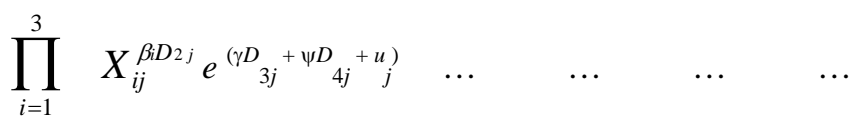

Equation (4.1) can be log-linearised as below:

$$
\begin{aligned}
& \ln Y_{j}=\alpha_{0}+\beta_{0} D_{1 j}+\beta_{0} D_{2 j}+\sum_{i=1}^{3} \alpha_{i} \ln X_{i j}+\sum_{i=1}^{3} \beta_{i} D_{1 j} \ln X_{i j}+ \\
& \sum_{i=1}^{3} \beta_{i} D_{2 j} \ln X_{i j}+\gamma D_{3 j}+\psi D_{4 j}+u_{j} \quad \ldots \quad \ldots \quad \ldots \\
& (j=1,2, \ldots \ldots \ldots \ldots . . . .)
\end{aligned}
$$

where $Y_{j}=$ wheat output per acre of $j$ th farm, $X_{1}=$ area operated in acres, $X_{2}=$ labour cost per acre which includes cost of own, hired, and exchange labour where labour wage is measured in rupees per day, and $X_{3}=$ capital services used per acre which includes costs on animal labour, seed, tractor and thresher use, farm-yard manures, seed treatment with fumigation, etc. The stochastic disturbance term, $u_{j}$, is assumed to have a zero mean and a uniform variance and is distributed independently of $X_{i}$. $D_{1}$ is dummy variable that takes the value of unity for (i) large farms (above 25 acres) and (ii) owner-operated farms; and zero otherwise. $D_{2}$ is dummy variable that takes the value of unity for (i) medium farms (12-25 acres) and (ii) owner-cumtenanted farms; and zero otherwise. $D_{3}=1$ if farmer is literate and 0 otherwise. $D_{4}=$ 1 if farmer has utilised extension services and 0 otherwise.

To test the hypothesis that the three groups of farms face the same production technology, we assume that the coefficients are the same in separate regressions for each group. If $\beta_{0}$ 's are statistically different for zero, then a shift in the neutral technically efficiency parameter is confirmed, which means that the two groups of farms for which $D_{1}=1$, and $D_{2}=1$, respectively, are technically more efficient than another group of farms for which $D_{1}=D_{2}=0$. Similarly, if the slope shift coefficients ( $\beta_{i}$ 's) are significantly different from zero, as revealed by a joint $F$-test, it is concluded that there are factor-biased differences in technology. On the other hand, if neither the intercept shift coefficients nor the slope shift coefficients prove to be different from zero, it is concluded that the three groups of farms face the same technology. If for any set of farms it is concluded that the technology is the same for both groups, then the production function is re-estimated over the entire sample. 


\section{ESTIMATION OF TECHNICAL EFFICIENCY}

The results of estimates of Equations (1 to 4 ) showed that Equation 4 was the best fit. Hence, the results of Equation (4) only are reported in Table 3. Regarding the regression results of the equation based on farm size, it can be concluded that small, medium, and large farms are not equally technically efficient. Therefore,

Table 3

Estimated Parameters of the Production Function for Rainfed Wheat, by Farm Size

\begin{tabular}{lccc}
\hline Description & Coefficient $^{\mathrm{a}}$ & Farm Size & $t$-values \\
\hline Intercept & $\alpha_{0}$ & 3.30 & $(2.3)^{* *}$ \\
& $\beta_{0} \mathrm{D}_{1}$ & 1.25 & $(2.65)^{* *}$ \\
& $\beta_{0} \mathrm{D}_{2}$ & 1.40 & $(3.4)^{*}$ \\
Land & $\alpha_{1}$ & 0.62 & $(2.6)^{*}$ \\
& $\beta_{1} \mathrm{D}_{1}$ & 0.12 & $(2.8)^{*}$ \\
& $\beta_{1} \mathrm{D}_{2}$ & 0.18 & $(2.3)^{* *}$ \\
Labour & $\alpha_{2}$ & 0.20 & $(5.3)^{* *}$ \\
& $\beta_{2} \mathrm{D}_{1}$ & 0.21 & $(6.1)^{*}$ \\
Capital & $\beta_{2} \mathrm{D}_{2}$ & 0.30 & $(2.1)^{* *}$ \\
& $\alpha_{3}$ & 0.06 & $(4.3)^{*}$ \\
& $\beta_{3} \mathrm{D}_{1}$ & 0.03 & $(5.2)^{* *}$ \\
Farmer Literacy & $\beta_{3} \mathrm{D}_{2}$ & 0.12 & $(2.2)^{* *}$ \\
Extension Services & $\gamma \mathrm{D}_{3}$ & 0.60 & $(2.4)^{* *}$ \\
Adjusted- $R^{2}$ & $\psi \mathrm{D}_{4}$ & 0.40 & 0.76 \\
F-stat. & $\mathrm{F}^{\mathrm{b}}$ & & 20.70 \\
Sample Size & & & 170 \\
\hline
\end{tabular}

Note: “*” and “**” show significance at 1 percent and 5 percent, respectively.

${ }^{\mathrm{a}} \mathrm{D}_{1}=1$ if large farms; 0 otherwise.

$\mathrm{D}_{2}=1$ if medium farms; 0 otherwise.

$\mathrm{D}_{3}=1$ if farmer is literate; 0 otherwise.

$\mathrm{D}_{4}=1$ if farmer has utilised extension services; 0 otherwise.

${ }^{\mathrm{b}} F$ tests the hypothesis that $\beta_{0}$ 's $=0$ and $\beta_{1}$ 's $=0$ for all $\mathrm{I}=1,2$, and 3 . That is, $F$ tests the hypothesis that all coefficients are the same in separate regressions for each group.

this leads to reject our hypothesis that small, medium, and large farms are equally technically efficient. If we examine the value of $F$, then it can be stated that 
the hypothesis that all coefficients are the same in separate regressions for small, medium, and large farms is also rejected at 5 percent level of significance. This conclusion is further supported by employing a two-tailed $t$-test to examine the significance of the coefficients on the individual factor shift variables. The regression results show that large farms are technically more efficient than small farms (that is, the neutral efficiency parameter is larger for large farms than for small farms) and medium farmers are relatively technically more efficient than both small and large farms. This is an important result which implies that the medium-sized farmers quickly pick up the modern techniques, and that they are the most efficient users of inputs relative to other farms. This may be because the small farmers do not have access to institutional inputs and lack affordability, so they are technically less efficient. On the other hand, large farmers, due to absenteeism and relatively high culturable waste, have lower efficiency than medium-sized farms. The coefficients of dummy variables for farmer literacy and farmers utilising extension services are also statistically significant at 5 percent, showing that literate farmers and those using extension services are producing more wheat per acre than illiterate farmers and farmers not using extension services, respectively.

If we examine the regression results for another set of farms based on tenurial categories, then it can be stated that tenanted, owner-cum-tenanted, and owneroperated farms are also not equally technically efficient (Table 4). Examining the values of $\mathrm{F}$ for this set of farms (i.e., tenanted, owner-cum-tenanted and owneroperated), it can be said that the hypothesis that all the coefficients are the same in separate regressions for each group is rejected at a 5 percent significance level. This conclusion is also further supported by employing a two-tailed $t$-test to examine the significance of the coefficients on the individual factor shift variables. It is concluded, therefore, that tenants, owner-cum-tenants, and owners are not equally technically efficient (that is, they face different technology and production functions). The results show that owner-operated farms are more efficient than both tenanted and owner-cum-tenanted farms (that is, the neutral shift parameter is larger for owner-operated farms than for tenanted and owner-cum-tenanted farms).

The results of the present study are in disagreement with Himayatullah et al. (1994), who found that small and large farms as well as owner-operated and tenanted farms were equally technically efficient. Similarly, the findings of this study are also different from Schultz (1964), who, in a now classic work, argued that peasant farmers were "poor but efficient". The reasons for the difference in results may be the different sample size and sample area and the different time-period. For example, Himayatullah et al. (1994) is based on irrigated farming systems of the Peshawar Valley, while the present study was conducted in the rainfed farming system of Lakki Marwat. The two areas are quite different from each other with respect to many aspects. 
Table 4

Estimated Parameters of the Production Function for Rainfed Wheat, by Tenurial Status

\begin{tabular}{|c|c|c|c|}
\hline Description & Coefficient $^{\mathrm{a}}$ & Tenurial Status & t-values \\
\hline \multirow[t]{3}{*}{ Intercept } & $\alpha_{0}$ & 2.9 & \\
\hline & $\beta_{0} \mathrm{D}_{1}$ & 1.67 & $(2.69)^{* *}$ \\
\hline & $\beta_{0} \mathrm{D}_{2}$ & 1.41 & $(2.63)^{* *}$ \\
\hline \multirow[t]{3}{*}{ Land } & $\alpha_{1}$ & 0.61 & $(3.4)^{*}$ \\
\hline & $\beta_{1} \mathrm{D}_{1}$ & 0.16 & $(2.8)^{*}$ \\
\hline & $\beta_{1} D_{2}$ & 0.11 & $(2.64)^{*}$ \\
\hline \multirow[t]{3}{*}{ Labour } & $\alpha_{2}$ & 0.19 & $(2.23)^{* *}$ \\
\hline & $\beta_{2} D_{1}$ & 0.29 & $(6.1)^{*}$ \\
\hline & $\beta_{2} D_{2}$ & 0.20 & $(5.3)^{*}$ \\
\hline \multirow[t]{3}{*}{ Capital } & $\alpha_{3}$ & 0.05 & $(2.1)^{* *}$ \\
\hline & $\beta_{3} \mathrm{D}_{1}$ & 0.10 & $(4.2)^{*}$ \\
\hline & $\beta_{3} D_{2}$ & 0.03 & $(3.3)^{* *}$ \\
\hline Farmer Literacy & $\gamma \mathrm{D}_{3}$ & 0.63 & $(2.12) * *$ \\
\hline Extension Services & $\psi \mathrm{D}_{4}$ & 0.42 & $(2.04)^{* *}$ \\
\hline Adjusted- $R^{2}$ & & & 0.76 \\
\hline$F$-stat. & $F^{b}$ & & 21.77 \\
\hline Sample Size & & & 170 \\
\hline $\begin{array}{l}\text { Note: “*” and “**” shov } \\
\begin{aligned}{ }^{a} D_{1} & =1 \text { if owner } \\
D_{2} & =1 \text { if owner } \\
D_{3} & =1 \text { if farme } \\
D_{4} & =1 \text { if farmer }\end{aligned}\end{array}$ & $\begin{array}{l}\text { ance at } 1 \text { perce } \\
\text {; } 0 \text { otherwise. } \\
\text { ant; } 0 \text { otherwise } \\
\text { e; } 0 \text { otherwise. } \\
\text { sed extension se }\end{array}$ & ercent, respectively. & \\
\hline \multicolumn{4}{|c|}{$\begin{array}{l}\text { b } F \text { test the hypothesis that } \beta_{0} \text { 's }=0 \text { and } \beta_{1} \text { 's }=0 \text { for all } \mathrm{I}=1,2 \text {, and } 3 \text {. That is, } F \text { tests the hypothesis } \\
\text { that all coefficients are the same in separate regressions for each group. }\end{array}$} \\
\hline
\end{tabular}

\section{CONCLUSIONS AND RECOMMENDATIONS}

It can be concluded that large and medium farms have a different production function from small farms either because of the differential access to information (techniques) or because of the difference in managerial efficiency. Even if they have the same production functions, their market behaviour is different, since small farms are family farms producing mainly for subsistence, while large farms are "capitalist farms" producing for the market. Small farms are less dependent on the market for their inputs, relying to a greater extent on family labour (for example). In the case of large and medium farms, the latter are relatively more efficient as they are efficient users of modern techniques. As for tenants, it could be argued that they are also on a different production function for reasons similar to those of small farmers. Due to 
insecurity of tenure, tenants may not make use of land-improving practices, and hence may be on an inferior production function than owners and owner-cum-tenant farms. However, owner-operated farms are relatively technically more efficient than owner-cum-tenant farms.

It may be concluded that the existing technology (neutral and non-neutral) is in favour of medium as well as owner-operated farms. In the input use component, these two groups of farms are better placed than other farms in respect of most of the inputs used. Since these are purchased inputs, the large and medium farms can afford to buy and use these inputs. It may, however, be argued that if small farms are given adequate access to the inputs, they may be at least equally technically efficient if not more productive than large and medium farms. Thus, the development of inputs and providing small farms with better access to these inputs by forming various agencies should go side by side to improve our traditional agriculture.

It may be mentioned that the findings of this study are limited to a particular area and crop. Before making any generalisation of the findings, this sort of study might be conducted in other areas and for other crops also.

\section{REFERENCES}

Bardhan, P. K. (1973) Size, Productivity, and Returns to Scale: An Analysis of Farm Level Data in Indian Agriculture. Journal of Political Economy 81:6 1370-86.

Barnum, H. N., and L. Squire (1978) Technology and Relative Economic Efficiency. World Bank Reprint Series No. 94. Reprinted with Permission from Oxford Economic Papers 30:2 181-98.

Bashir, M., and Himayatullah (1994) Analysis of Relative Technical Efficiency of Wheat Growers in Rainfed Farming System of Lakki Marwat. Final Report of TIPAN Special Project.

Battese, G. E., T. J. Coelli, and T. C. Colbi (1989) Estimation of Frontier Production Functions and the Efficiencies of Indian Farms Using Panel Data from ICRIST's Village Level Studies. Journal of Quantitative Economics 5: 32748.

Battese, G. E., and T. J. Coelli (1992) Frontier Production Functions, Technical Efficiency and Panel Data: With Application to Paddy Farmers in India. The Journal of Productivity Analysis 3: 149-69.

Fare, R., S. Grosskopf, and C. A. K. Lovell (1985) The Measurement of Efficiency of Production. Dordrecht: Kluwer-Nijhoff.

Farrell, M. J. (1957) The Measurement of Production Efficiency. Journal of the Royal Statistical Society 120: 253-81.

Himayatullah, M. A. Chaudhary, and M. K. Shah (1994) Measurement of Relative Technical Efficiency in Agriculture: A Case Study of Peshawar Valley. Journal of Economics 1:1 49-55. 
Humphrey, D. H., and H. S. Oxley (1976) Expenditure and Household Size Elasticities in Malawi: Urban-Rural Comparison, Demand Projection and Survey of East African Findings. Journal of Development Studies 12:2 252269.

Kalirajan, K. P. (1990) On Measuring Economic Efficiency. Journal of Applied Econometrics 5: 75-85.

Kalirajan, K. P., and J. C. Flinn (1983) The Measurement of Farm-Specific Technical Efficiency. Pakistan Journal of Applied Economics 2: 167-80.

Nowsherwani, V. F. (1966) Allocative Efficiency in Traditional Indian Agriculture: Comment. Journal of Farm Economics 49: 218-21.

Schultz, T. W. (1964) Transforming Traditional Agricultural. New Haven: Yale University Press.

Zellner, A., J. Kmenta, and J. Dreze (1966) Specification and Estimation of CobbDouglas Production Function Models. Econometrica 34: 784-95. 


\section{Comments}

In Pakistan, the new technology in agriculture was introduced in the early 1960s. It has undoubtedly increased crop yields significantly and has enabled the agricultural output to grow, on average, by 4 percent per annum since the 1960s. At least three pertinent questions arise regarding the introduction of the new technology:

(i) What has been the progress in the adoption of technology in different crop areas?

(ii) Did the growth rates of the agricultural output in different areas improve after the introduction of new technology?

(iii) Is the new technology alone responsible for the growth of output in different farm sizes and tenurial categories?

The paper focuses on the last question. In particular, it tries to ascertain the behaviour of wheat producers in terms of their relative technical efficiency by farm size and tenurial status.

Technical efficiency takes place either through the acquisition of new machines, including improved production techniques, i.e., embodied technical change, or with the improvements in the management quality of human resources and learning by doing, i.e., disembodied technical change. This paper focuses only on the embodied technical change.

The classification of farms, as small and large, made in this paper is totally arbitrary. The paper provides no reason as to why the 60:40 ratio of the small and large farms has been used, or whether this ratio is representative of the total farms size distribution of the area. Farms between 12 and 25 acres have not been included in the analysis. If those farms are unimportant for the purposes of this analysis is not clear? In fact, many studies have shown that it is the medium-sized farmers who quickly pick up the modern techniques. Eshya and Hanid (1988) found that the medium-sized farms (5-25 acres) are the most efficient group of farmers.

It is not clear from the paper how different variables are computed, and whether they are used as stock variables or flow variables? Although it is reported in the paper that capital and labour services are used, but it is not clear how they are computed because in such a survey, normally, one either gets responses on the stock of capital or for the rental values if the machinery is rented. Similarly, regarding labour, its unit of measurement is not reported, whether it is hourly wage per acre or something else. Unless one describes these, it is hard to know the precise implications of the estimated coefficient.

The paper uses a Cobb-Douglas production function framework relating wheat output to the inputs of land and the services of capital and labour. Given the detailed data collected in the survey, one would like to see the use of other specifications such as Translog Production Function which, unlike a Cobb-Douglas production function, 
does not place a priori restriction on the substitution possibilities among the factors of production, that is, it permits a greater variety of substitution and transformation patterns of frontier than the Cobb-Douglas production function, which is based on constant elasticity of substitution and transformation. Thus efficiency gains, computed on the basis of false assumption, will certainly be subject to substantial errors.

The author uses the output of wheat of the farm instead of using the yield. In an analysis of technical efficiency, the better variable to use is the output per acre. The use of per acre yield would also help to overcome the estimation bias.

The use of gross output of wheat as the dependent variable, instead of the value-added, leaves room for the introduction of some more explanatory variables, such as extension service, access to markets, and education of farmers, to be included in the analysis. These variables play an important role in enhancing the crop yield. The omission of these variables from the analysis can affect the reported residual which reflects the technical efficiency.

The analysis would have been more meaningful had the author considered the interaction of variables in the following manner; that, is using two separate dummies for the large and small farms in a regression while dividing these dummies by tenurial status. Similarly, the analysis of efficiency differentials for educated vs uneducated farmers can provide additional insights. For example, the education variable is important because it facilitates the acquisition of information about the use of institutional inputs, and makes farmers more capable of using physical inputs in the best possible way.

The findings of this paper, which are based on 100 observations of a district in the NWFP, cannot be generalised especially when they are not in agreement with other studies, and also for the fact that medium-sized farms have been ignored. Small farmers, generally, do not have access to institutional inputs and lack affordability; so they are technically less efficient. Large farmers, too, due to neglect in farming, say because of absenteeism and relatively high culturable waste, have low efficiency. As compared to the small and large farmers, the medium-sized farmers, due to affordability and better management of resources, are the most efficient group of farmers.

Zafar Mahmood

Pakistan Institute of

Development Economics,

Islamabad.

\section{REFERENCE}

Mukhtar, Eshya Mujahid, and Hanid Mukhtar (1988) Input Use and Productivity across Farm Sizes: A Comparison of the Two Punjabs. The Pakistan Development Review 27:4. 